\title{
NOTAS SOBRE CONSTITUIÇÃO DO SUJEITO, SUBJETIVIDADE E LINGUAGEM
}

\author{
Susana Inês Molon
}

\begin{abstract}
RESUMO. Este artigo discorre sobre a constituição do sujeito e da subjetividade na abordagem sócio-histórica, trazendo para discussão a questão da linguagem e produção de sentido em autores contemporâneos estudiosos de Vygotsky. O estudo é teórico e contextualiza a elaboração conceitual da obra de Vygotsky, a qual é marcada pela complexidade e inacabamento, condições que geram diversidades nas/das interpretações entre os autores. Busca-se explicitar e compreender as diferentes noções de sujeito e de produção de sentido entre eles. Para tanto são levadas em conta as contribuições de González Rey na sua argumentação sobre a dimensão subjetiva do sentido pessoal e da subjetividade individual e social. Ao se retomar o pensamento de Vygotsky, tem-se como interlocutor Bakhtin, dialogando com autores que, com fundamento no materialismo histórico e dialético, possibilitam compreender o sujeito constituído pelo outro e pela linguagem, enfocando drama, subjetividade e produção de sentido nos aspectos interconstitutivos das múltiplas dimensões - singular e coletiva, subjetiva e objetiva, biológica e cultural, histórica e dialética.
\end{abstract}

Palavras-chave: constituição do sujeito; subjetividade; linguagem.

\section{NOTES ON THE CONSTITUTION OF THE SUBJECT, SUBJECTIVITY AND LANGUAGE}

\begin{abstract}
The following article discusses the constitution of the subject and the subjectivity on the sociohistorical approach, making evident the question of the language - production of meaning in Vygotskian contemporary authors. This theoretical study contextualizes the conceptual elaboration of Vygotsky's work, marked by complexity and incompleteness that generate diversity in/of interpretations among authors. It attempts to undercover and understand the different notions of subject and production of meaning between them. To this end, González Rey's contributions support the idea of subjective dimension of personal meaning and individual and social subjectivity. Such ideas resume the Vygotskian thinking, considering Bakhtin as an interlocutor, dialoging with authors based in the historical and dialectical materialism, which makes possible to understand the subject constituted by the other and constituted by language. Such features enables the focus on drama, subjectivity and meaning production in interconstitutive aspects of multiple dimensions - singular/collective, subjective/objective, biological/cultural, historical/dialectical.
\end{abstract}

Key words: Subject constitution; subjectivity; language.

\section{APUNTES SOBRE CONSTITUCIÓN DEL SUJETO, SUBJETIVIDAD Y LENGUAJE}

RESUMEN. Este artículo trata de la constitución del sujeto y subjetividad bajo el enfoque socio-histórico, discutiendo el lenguaje - la producción de sentido en autores contemporáneos, estudiosos de Vygotsky. Es un estudio teórico que contextualiza la elaboración conceptual de la obra de Vygotsky, enmarcada por la complejidad y lo incompleto, que ha generado diversidad de interpretación. Se busca explicar y entender las diferentes nociones de sujeto y de producción de sentido, considerando contribuciones de González Rey en la argumentación de la dimensión subjetiva del sentido personal y subjetividad individual y social. Se reanuda el pensamiento de Vygotsky, dialogando con Bajtín y otros autores basados en el materialismo dialéctico e histórico, comprendiendo el sujeto constituido por el otro y por el lenguaje, centrándose en el drama, subjetividad y producción de sentido en los aspectos interconstitutivos de múltiples dimensiones - singular y lo colectivo, subjetivo y objetivo, biológica y cultural, histórico y dialéctico.

Palabras-clave: Constitución del sujeto; subjetividad; lenguaje.

Doutora em Psicologia Social pela Pontifícia Universidade Católica de São Paulo - PUC/SP, com Pós-doutorado em Educação na Universidade de Campinas - UNICAMP. Professora Associada da Universidade Federal do Rio Grande - FURG, Brasil. 
As temáticas do sujeito e da subjetividade surgiram com a ciência moderna e suas emergências na psicologia (fortemente influenciada pela epistemologia dominante na época, o pensamento naturalista e positivista) e estiveram subordinadas à disciplina, ao controle, à adaptação, à instrumentalidade e à utilidade (Figueiredo, 1991; Molon, 2003). O conhecimento psicológico passa a ser constituído ao longo do século XX com a marca das reduções conceituais e metodológicas, o que provocou inúmeras polêmicas teóricas e metodológicas que, por sua vez, sustentam concepções e posições bastante diferentes. Na contemporaneidade, pergunta-se constantemente de que sujeito se fala, que sujeito está presente nas diversas teorias, se o sujeito é agente ou produto, ativo ou passivo, autônomo ou prisioneiro, livre ou assujeitado, interativo ou semiótico (da consciência, da atividade, da linguagem, do inconsciente); se é construído ou constituído (na história, nas relações sociais, nas narrativas, nas estruturas biológicas e cognitivas) de determinações internas e/ou externas; se é gerador/fornecedor de sentidos pessoais ou negociador de sentidos coletivos; ou ainda, se é sem sentido, vazio, ou efeito de várias posições e contingências ou imanência psíquica, ou poderia ser tudo isso, dialeticamente, dependendo do(s) lugar(es) que o sujeito ocupa na sociedade de classes sociais antagônicas.

Ante a ideologia pós-moderna e a compreensão da lógica da mercadoria,com base no marxismo, receia-se que essa negociação de sentidos fique deveras limitada. A subjetividade é entendida nas mais diversas formas: como intrapsicológica, como referente ao mundo privado, por configurações subjetivas, intersubjetividade, como resultante de cruzamento de fluxos linguísticos e agenciamentos sociais - portanto, está submissa ou sobreposta às condições sociais, históricas, linguísticas e psicológicas. Dentro disso, indaga-se se o sujeito existe ou não; se a subjetividade interfere ou não nos processos de construção do conhecimento; e se a produção de sentido é uma dimensão subjetiva e individual ou relacional e coletiva.

Nesse contexto, faz-se um recorte para analisar a constituição do sujeito e da subjetividade na abordagem sócio-histórica. Os questionamentos propostos são: como essa abordagem dá conta dessas temáticas e de que maneira o faz? Como rompe ou não com as visões subjetivistas e individualistas do sujeito e da subjetividade? Como supera ou não as dicotomias e os dualismos entre o individual e o coletivo, o biológico e o cultural, a emoção e a razão, a objetividade e a subjetividade? Como estão sendo produzidas as colaborações em torno dessas questões, partindo-se do princípio de que as relações humanas são fundantes dos sujeitos?

\section{A COMPLEXIDADE E O INACABAMENTO DA OBRA DE LEV S. VYGOTSKY}

A procura da definição de alguns conceitos ou de alguns termos na obra vygotskiana precisa considerar e contextualizar alguns pontos, entre eles: 1) Vygotsky não deixou uma teoria pronta e acabada, e não se sabe se era intenção dele fazê-lo, tendo-se em conta a sua morte prematura; 2) seus constantes e graves problemas de saúde intensificaram sua escrita; 3) o caráter intenso e variado da sua produção mostrava seu trânsito entre diversas áreas do conhecimento, como as ciências humanas, as artes e a literatura; 4) seus interesses abrangiam diferentes campos e temáticas, como os processos de criação artística e estética, porém ele centrou-se na Psicologia; 5) discutiu as mais diversas concepções psicológicas, sendo ainda hoje revolucionária a sua maneira de conceber o fenômeno psicológico ao introduzir a mediação semiótica; 6) suas ideias foram censuradas, alguns textos foram encontrados somente muitos anos após sua morte; 7) não revisou seus escritos; sua obra enfrenta vários problemas de tradução, principalmente os textos que passaram pelo crivo da psicologia norteamericana.

Além dessas razões, as quais refletem a complexidade e o inacabamento de sua obra, outro ponto que merece ser discutido é seu trabalho de elaboração conceitual. Cabe destacar que ele se propôs a construção de uma nova Psicologia, apostando na emergência de um novo homem, e isso era o conteúdo que marcava sua escrita. Seus textos carregam a intensidade de sua criação. Com isso expressam os diferentes significados e sentidos que ele usava para uma mesma palavra, como é o caso, por exemplo, dos termos "signo" e "consciência", cujos conceitos aparecem de formas diferentes ao longo de sua obra. Assim, de um lado, pode-se dizer que o autor estava sendo coerente com a abordagem que estava construindo, na qual as palavras são polissêmicas e apresentam sentidos variados; e de outro, encontra-se "quase total ausência de definições dos termos que ele utiliza, mesmo tratando-se de termos-chave para a construção desse pensamento" (Pino, 2005, p. 95). Acredita-se que isso esteja vinculado ao seu estilo dialético de pensamento - marcado pelo enfrentamento das ambiguidades e das contradições, avanços e hesitações conceituais, superações teóricas e metodológicas. Daí a necessidade de se tentar 
compreender os diferentes significados e sentidos atribuídos às mesmas palavras na elaboração conceitual do seu pensamento, isto é, de procurar as explicações e as implicações dos diversos modos de fazer sentido em cada texto e nos diferentes contextos de sua produção.

Pode-se dizer que a obra de Vygotsky contrapõese ao modelo positivista $\mathrm{e}$ à racionalidade instrumental, de modo que entender seu pensamento exige esforço e determinação. Compreende-se, por exemplo, o escrito aqui sempre buscando o dito lá e acolá, o texto, o intertexto e o subtexto. Para aqueles que cobram uma precisão conceitual, pode-se dizer que "essa procura da segurança de uma teoria perfeita, totalizada, é a heresia original contra o conhecimento (Thompson, 1981, p. 183).

$\mathrm{Na}$ trama conceitual tecida na urdidura de sua obra, tendo-se presente a sua história de vida e o contexto histórico-político-cultural e científico da sua época, é possível afirmar que seu pensamento contribui significativamente para o debate sobre o sujeito e a subjetividade no campo das ciências humanas.

Os autores contemporâneos reconhecem e valorizam os pressupostos básicos da perspectiva por ele formulada, os quais podem ser traduzidos no entendimento do homem na dimensão das leis sóciohistóricas e culturais, e não mais na ordem das leis naturais e do estritamente biológico (modelo biológico, naturalista, que concebe o homem em termos de simples organismo, ignorando a especificidade humana), tal como é compreendido por outras teorias psicológicas. $\mathrm{Na}$ abordagem sóciohistórica tem-se por pressuposto a origem e a natureza social e histórica do sujeito.

Não obstante, a análise da natureza da participação da realidade social na constituição do sujeito e a conceituação da gênese dos processos psicológicos no sujeito geram controvérsias e explicações ambíguas, demarcando um debate entre os especialistas que tendem a privilegiar determinados conceitos na busca de explicitação dos princípios e de explicações plausíveis para o funcionamento inter e intrapsicológico (Smolka, Góes e Pino, 1998; Molon, 2003).

Pela complexidade, diversidade e incompletude da obra de Vygostky, os diversos modos de apropriação do seu pensamento evidenciam a necessidade de reconhecer a heterogeneidade das ideias por ele produzidas e a diversidade de suas interpretações entre os autores, permitindo que se produza um pensamento não indiferente sobre as questões não coincidentes, mas que se busque explicitar e compreender as sutilezas, as nuanças, os indícios, os vestígios presentes nos diversos autores.

Isso é particularmente instigante quando se procura compreender as noções de sujeito, subjetividade e produção de sentido nesse campo de investigação teórica e metodológica, uma vez que se destacam as particularidades nas/das diferenças. Acredita-se que essa diversidade conceitual não pode significar a ausência de fundamentos nem a adesão ao pluralismo e ao relativismo absoluto. É possível que não se encontrem definições e preceitos precisos na obra de Vygotsky, pois sua leitura requer, também, que o estudioso acompanhe as fases de elaboração dos conceitos de cada obra em análise, considerando-se o próprio amadurecimento teórico do autor $\mathrm{e}$ as condições objetivas de suas elaborações, já que os pressupostos e os princípios estão bem definidos.

\section{CONCEPÇÕES DE SUJEITO, DE SUBJETIVIDADE E DE SENTIDO PESSOAL}

Entre os autores que aderem aos princípios propostos por Vygotsky e analisam a constituição do sujeito priorizando a dimensão subjetiva, destaca-se a presença significativa de Fernando González Rey. Esse autor contemporâneo contribuiu para o debate da questão do sujeito e da subjetividade ao defender a noção de sentido pessoal, gerando uma distinção entre a dimensão social e coletiva do significado e a dimensão subjetiva do sentido, além de elaborar o seu marco conceitual criando uma distinção entre a subjetividade individual e a subjetividade social.

González Rey (1997) propõe outra configuração teórica e metodológica para a Psicologia, fundamentada na epistemologia qualitativa e na questão do sujeito, da personalidade e da subjetividade. Para ele, a subjetividade é a constituição da psique no sujeito individual e é integrada também pelos processos e estados característicos a este sujeito em cada um de seus momentos de ação social, os quais são inseparáveis do sentido subjetivo que tais momentos terão para ele. $\mathrm{Na}$ sua elaboração teórica, defende que a subjetividade está organizada por processos e configurações que se interpenetram permanentemente, estão em constante desenvolvimento e vinculados à inserção simultânea do sujeito em outro sistema igualmente complexo, que é a sociedade, dentro da qual o sujeito tem de seguir os desafios e contradições de se desenvolver através de sistemas diversos, nos quais ele não é mais que um dos elementos constituintes, sistemas que não se organizam necessariamente de acordo com as 
necessidades atuais de organização e desenvolvimento de sua subjetividade individual.

Desse modo, o sujeito precisa encontrar formas de relação e de ação compatíveis com a organização e desenvolvimento de sua subjetividade individual e com sua inserção nos diferentes sistemas de relações em que se constitui. Este é um processo permanente de crescimento ou involução, e a ele o autor atribui, nas múltiplas e contínuas reconfigurações da subjetividade, um caráter social e histórico. Destarte, o autor não se refere à subjetividade como um fenômeno homogêneo nem unidimensional, mas como um sistema processual. Apresenta uma concepção sistêmica do funcionamento psicológico, permanecendo a ideia de um sujeito individual ativo, centrado nas suas (re) configurações subjetivas e autônomo em relação ao outro; de um sujeito que gerencia constantemente uma organização funcional própria e apresenta um desenvolvimento sistêmico tendente à estabilidade. Psique, personalidade, subjetividade, configurações subjetivas, sentidos subjetivos são vistos como sistemas que têm formas de organização próprias e se apresentam relativamente estáveis, e cujo sentido é gerado pelo sujeito, pois "o sentido é uma verdadeira produção subjetiva, uma vez que não se define pela ação direta de um evento social" (González Rey, 2005, p. 45).

Na sua proposta, o autor distingue a subjetividade individual e a subjetividade social, observando que simultaneamente a subjetividade se expressa em nível social como constituinte da vida social. Esse momento é por ele denominado de subjetividade social, porém esta não se diferencia da individual por sua origem, mas sim, pelo cenário de sua constituição. Cabe salientar que essa distinção é de difícil compreensão em uma posição dialética, mesmo o autor argumentando que a subjetividade individual, pelas múltiplas determinações do real, assume o caráter de condicionante social, porém não na forma de um determinismo linear externo, do social para o interior, para o subjetivo, mas em um processo de constituição que integra de forma simultânea as subjetividades social e individual. $\mathrm{O}$ sujeito é um elemento constituinte da subjetividade social e, simultaneamente, constitui-se nela.

A proposta de González Rey (1997, 1999, 2001a, 2001b) tem como foco a dimensão subjetiva do sujeito, tanto que ele argumenta que existe um processo de auto-organização da subjetividade que está relacionado às necessidades do sujeito; e uma vez constituída em suas formas primárias, a subjetividade se converte, dentro de cada sujeito concreto, no próprio cenário de seu desenvolvimento. Assim, as necessidades do sujeito estão relacionadas com o processo de auto-organização da sua subjetividade, bem como com as exigências do contexto social no qual ele está inserido, o que aparece como processo permanente de sua condição existencial. As necessidades constituídas neste processo respondem a caminho único dentro do qual se estrutura a história subjetiva de cada sujeito concreto na sua condição social, diferenciando-se essencialmente das necessidades biológicas, não só pelo conteúdo, mas também por sua própria natureza dinâmica (González Rey, 1997).

González Rey (2001b) especifica o caráter subjetivo do sentido, buscando diferenciar seu uso das perspectivas que o mantêm indissociavelmente associado com as práticas discursivas, bem como procura se diferenciar das interpretações mais objetivistas apresentadas por A. N. Leontiev, ao definir o sentido pessoal em termos da atividade. A preocupação de não reduzir o sujeito a meras convenções do discurso, apesar de reconhecer o diálogo como cossubstancial aos processos de configuração subjetiva do sujeito, leva González Rey a não relevar a dimensão semiótica na constituição do sujeito e da subjetividade.

Ao privilegiar, assim, as configurações subjetivas e o sentido pessoal, González Rey deixa algumas questões com relação à concepção, ao problema da significação e ao papel da linguagem na constituição do sujeito. $\mathrm{O}$ autor rompe com as definições transcendentais e com as categorias invariáveis e universais situadas no intrapsíquico, mantendo, no entanto, uma noção de autorreferência, com uma visão centrada no sujeito.

\section{RETOMANDO O PENSAMENTO DE LEV S. VYGOTSKY}

Neste estudo teórico sobre a constituição do sujeito e subjetividade na abordagem sócio-histórica, no qual se ressalta a questão da produção de sentido, as obras de Lev S. Vygotsky que subsidiam as análises e reflexões são: Obras Escogidas III: Problemas del desarrollo de la psique, Historia del desarrollo de las funciones psíquicas superiores; Pensamento $e$ linguagem; Teoria e método em psicologia; A construção do pensamento e da linguagem; e o Manuscrito de 1929.

É importante retomar as ideias de Vygotsky em diálogo com autores contemporâneos que realizam uma leitura da sua obra com base no materialismo histórico e dialético, pois isto possibilita compreender o sujeito constituído pelo outro e pela linguagem, 
enfocando-se as relações dialéticas das dimensões intrapsicológica e interpsicológica para além das situações específicas e harmônicas de intersubjetividade.

Vygotsky sempre compreendeu os processos psicológicos tendo presente no plano teórico/conceitual e epistemológico/metodológico as unidades de análise para a problematização e a compreensão das relações constitutivas singulares e coletivas, biológicas e culturais, históricas e dialéticas, afetivas e cognitivas, objetivas e subjetivas. Essa marca de Vygotsky propicia a superação de dicotomias presentes na psicologia.

A complexidade das elaborações conceituais de Vygotsky (1993, 1995, 1996, 2000, 2001) aponta para a necessária prudência relacionada à eleição de uma única categoria de análise - como atividade, consciência, sentido, significado - , e exige o tensionamento e a consideração dos aspectos interconstitutivos das múltiplas dimensões individual, social e histórica, coletiva - para a compreensão do sujeito e da subjetividade.

Desse modo, é possível elaborar, nessa trama conceitual, uma concepção de sujeito, de subjetividade e de produção de sentido. Se não se tem uma teoria acabada e fechada, tem-se a o tecido teóricometodológico urdido não na racionalidade técnica e instrumental, mas nas imbricações das dimensões afetivas e cognitivas, estéticas e éticas, que possibilitam a compreensão da natureza e da dinâmica dos processos constitutivos e constituintes do sujeito, da subjetividade e da intersubjetividade, que estão sempre e necessariamente implicados uns aos outros.

Quando Vygotsky (2000, p. 33) afirma que "o homem é o conjunto das relações sociais encarnado no indivíduo" ressalta que essas relações são fundantes dos sujeitos. A questão do sujeito está nas relações sociais e nas práticas sociais, na dinâmica dialética entre o funcionamento interpsicológico e o funcionamento intrapsicológico, transição que acontece pelas mediações semióticas. Deve-se problematizar as (im)possibilidades de constituir sujeitos imersos nas práticas sociais em um determinado contexto.

Vygotsky (2000, p. 27) argumenta que "as funções psicológicas superiores são desenvolvidas na forma de drama", que "a dinâmica da personalidade é o drama" (p. 35); portanto, "a psicologia não pode apresentar-se nos conceitos dos processos, mas do drama" (p. 38), pois a noção de drama enfatiza a complexidade e a interconstituição dos processos. Vygotsky explicita essa noção do drama referindo a Politzer, no Manuscrito de 1929, a Psicologia concreta do homem, no qual considera que "o drama sempre está repleto de luta" (p. 35). Vygotsky argumenta que a consciência é histórica e semioticamente constituída e que o drama constitui o sujeito nas tramas das/nas relações imersas nas práticas sociais.

Para ele, a Psicologia "humaniza-se" na compreensão de que viver a vida não é apenas um evento circunstancial, nem somente um episódio ocasional, mas é o modo de ser do sujeito nas relações e práticas sociais, no acontecimento que se dá em um determinado contexto concreto e histórico, engendrado pelas diferentes posições sociais ocupadas e pelo lugar singular que cada um ocupa num dado momento. A vida está repleta de lutas, o viver é o drama. O sujeito vive no mundo da realidade inescapável. A constituição do sujeito é dramática, é "choque dos sistemas", e se dá na forma de drama; portanto o drama é a condição de vida e também o modus operandi do sujeito.

Vygotsky busca compreender o vivido por "dentro" que veio de "fora", mas que não se cristaliza, não se torna estático ou estável, porém não é inefável nem indolor, pelo contrário, é significativamente sentido e vivido nas experiências, nas pausas, nas (in)determinações das in(ter)venções e nas situações em que o sujeito se posiciona. Coloca-se, então, o problema do outro: qual o alcance do outro, o que o outro capta, qual é o alcance de cada um, o que cada um capta. $\mathrm{O}$ olhar do outro sempre será diferente, mas precisa-se dele para se enxergar de forma diferente. Nessa perspectiva, o sujeito é uma unidade múltipla que se realiza na relação Eu-outro; ou seja, é na relação com os outros e por ela, é na linguagem e por ela que alguém se constitui sujeito e é constituinte de outros sujeitos (Molon, 2003).

Disso se infere que a relação do sujeito com o outro é mediada. Assim, todas as relações são mediadas, e nem as interações epistemológicas nem as dialógicas são diretas; da mesma forma, as relações entre pensamento e linguagem não são diretas, mas são mediadas pelo significado. Desse modo, o sujeito se constitui pela mediação semiótica e por meio do processo de significação, mas essa constituição acontece no confronto eu-outro das relações sociais. Nesse sentido, a subjetividade e o sujeito são compreendidos na realidade social e na vida social, vista esta como, primordialmente, histórica.

Nessa trama constitutiva do sujeito acontece o drama vivo do pensamento e da linguagem pelas mediações semióticas; assim, tanto os significados das palavras (zonas quase estáveis da significação) quanto os sentidos (zonas mais instáveis da significação) possibilitam processos de produção de subjetividade. 
A subjetividade constituída e constituinte nas/das diversas zonas de estabilidade variada do sentido sendo também fluida, dinâmica, complexa, que comporta uma zona uniforme e exata que é o significado, já que é próprio do signo - é convencional e dicionarizada, como defende Vygotsky (2001).

Se o sentido é constitutivo da subjetividade, essa acontece de forma inconstante, móvel, mutável, não coincidente com o significado da palavra, não fixada pelo signo. Esta flexibilidade-reversibilidademobilidade-instabilidade, não sendo coincidência característica do sentido, não faz dele algo individual, imediato, autônomo, regulado e estável. Os sentidos precisam ser forjados, enraizados, enriquecidos, incorporados, absorvidos no/do contexto no qual as relações e as práticas sociais são tecidas e entrelaçadas. As palavras mudam de sentido em contextos diferentes, mas são materializadas, concretizáveis, visualizadas no processo de comunicação entre os sujeitos.

"O sentido de uma palavra é a soma de todos os fatos psicológicos que ela desperta em nossa consciência" (Vigotski, 2001, p. 465). Nesses termos, "o sentido da palavra é inesgotável" (p. 466). Além disso, o autor chama a atenção para o "influxo de sentido" (1993, p. 126), isto é, "os sentidos como que deságuam uns nos outros e como que se influenciam uns aos outros, de sorte que os anteriores como que estão contidos nos posteriores ou os modificam" (2001, p. 469). Essa ideia de influxo (influência ${ }^{1}$ ) de sentido evidencia a dinamicidade, a flexibilidade, a mobilidade, a amplitude e a complexidade do sentido.

$\mathrm{O}$ sentido da palavra está relacionado à riqueza das experiências sociais e históricas que conformam as consciências e aquilo que pode ser expresso por uma determinada palavra. O significado de uma palavra é mais estável e preciso, enquanto o sentido é inesgotável. A palavra é polissêmica e fonte inesgotável de novos sentidos. A modificação do sentido de uma palavra depende tanto das situações quanto dos sujeitos que o atribuem, por isso ele é considerado quase ilimitado; porém os processos de significação são produzidos e apropriados nas relações sociais, em determinadas condições históricas.

Assim, é preciso reconhecer que as palavras são polissêmicas e as vozes são polifônicas; há múltiplos

1 Na tradução do livro Pensamento e linguagem, de 1993 feita por Jeferson Luiz Camargo aparece a expressão "influxo de sentido", e na tradução do texto integral, traduzido do russo Pensamento e linguagem, na obra intitulada "A construção do pensamento e da linguagem", realizada por Paulo Bezerra, consta a denominação de "influência do sentido". sentidos para aquilo que foi dito e para o que não foi dito, mas que foi pensado e assumido (pressuposto, subentendido). É necessário que o pensamento seja realizado (ele não apenas se expressa na palavra) nas palavras significadas (elas não são sons vazios), para ser possível (re)definir, (re)(in)formar, (re)inventar e (re)criar processos fundamentais na constituição do sujeito e da subjetividade (Molon, 2003, 2009).

Argumenta-se, então, que a constituição do sujeito não se esgota no privilégio de aspectos intrapsicológicos ou interpsicológicos, mas no processo dialético de ambos, e ainda - o que é mais expressivo - a constituição do sujeito acontece pelo outro e pela linguagem em uma dimensão semiótica. Sendo a palavra e o signo polissêmicos, a natureza e a gênese do processo de constituição do sujeito implicam, necessariamente, o diferente e o semelhante (Smolka, Góes e Pino, 1998).

Neste universo de discussões centralizado na concepção da constituição semiótica do sujeito, este se constitui pelo outro e pela linguagem por meio dos processos de significação e dos processos dialógicos, rompendo com a dicotomia entre sujeito e social, entre o eu e o outro. A alteridade aparece como fundamento do sujeito, e a linguagem, a mediação semiótica, a significação, como a questão molecular na obra de Vygotsky.

Góes (1993) ressalta a complexidade, na composição teórica da análise, da constituição do sujeito que pressupõe, ao mesmo tempo, a intersubjetividade constitutiva e a singularidade desse sujeito, pois somente assim será possível superar a concepção do sujeito abstrato, tanto do modelo universal quanto do modelo das diferenças individuais, ambos presentes tradicionalmente na Psicologia.

A concepção da constituição do sujeito em uma dimensão semiótica não ignora a individualidade nem a singularidade, mas atribui-lhes novos significados, quais sejam, a individualidade como um processo e como socialmente construída, a singularidade como uma conjugação que envolve elementos de convergência e divergência, semelhanças e diferenças, aproximação e afastamento em relação ao outro, e o sujeito como uma composição não harmônica dessas tensões e sínteses (Góes, 1993). A constituição do sujeito acontece no campo da intersubjetividade, configurado como o lugar do encontro e do confronto e como o palco de negociações dos mundos de significação privado e público.

Góes (1993) e Smolka (2000, 2004, 2006a, 2006b) evidenciam a complexidade da constituição do sujeito e da constituição da subjetividade, como 
também a importância da participação do outro na constituição do sujeito e da subjetividade. A participação do outro acontece em um cenário de agitação, conflito, produção permanente, diferenças, semelhanças e tensões, ou seja, em um cenário constituinte e constituído de significações, isto é, situado no mundo das significações.

A constituição implica a reciprocidade, a mutualidade e a organização semiótica. Neste sentido, um participa do outro no acontecimento social que acontece na dinâmica dialógica, na dinâmica dessas (inter-)relações.

Como sujeitos, os indivíduos são afetados, de diferentes modos, pelas muitas formas de produção nas quais eles participam - também de diferentes maneiras; ou seja, os sujeitos são profundamente afetados por signos e sentidos produzidos nas (e nas histórias das) relações com os outros. (Smolka, 2000, p. 31)

\section{ALGUMAS CONSIDERAÇÕES E POSSÍVEIS APROXIMAÇÕES TEÓRICAS}

Vive-se em uma arena de lutas com implicações teóricas e metodológicas que estão definindo um campo de investigação e se contrapondo a outros olhares e fazeres. Considera-se que a questão do sujeito, da subjetividade e da produção de sentido constitui um dos grandes desafios para as ciências humanas, especialmente para a Psicologia e a Educação.

Pelo que foi visto e argumentado, o importante é buscar dialogar com autores que compartilhem os pressupostos e interpretações da obra de Vygotsky, considerando suas especificidades, seus interesses de pesquisa e suas construções teóricas e metodológicas, o que constitui um campo permanente de reflexões, revisões, aprofundamentos conceituais.

Ao aprofundar as discussões, podem-se compreender, nas abordagens analisadas, suas particularidades e suas implicações nos modos de produzir conhecimento. $\mathrm{O}$ sujeito e o social são mutuamente constituídos e reciprocamente constituintes, e o processo de significação envolve e condensa todas as suas manifestações, expressões, sentimentos e emoções, afecções; portanto, seu corpo, sua atividade, sua consciência, sua vivência e sua experiência são atravessados e realizados pelos processos de produção da significação.

A maneira de compreender a significação e a produção de sentidos distingue as diversas tendências.
Do ponto de vista aqui assumido, a significação não é propriedade nem das coisas nem de suas representações: ela pertence à ordem da intersubjetividade anônima, conforme aponta Pino (1992). A subjetividade, a intersubjetividade face a face e a intersubjetividade anônima são constituintes e constituídas reciprocamente.

Nesse sentido, os estudiosos de Vygotsky que tematizam e investigam o modo de participação e de funcionamento do outro na constituição de sujeitos compreendem a multiplicidade de produções de sentidos, e o sentido não é, portanto, restrito à esfera individual. As contribuições de Vygotsky e Bakhtin (poderíamos mencionar também Wallon) ajudam-nos a compreender a polissemia da palavra sentido, que envolve e condensa múltiplas dimensões em tensão dialética e interconstitutiva: sentido relacionado à sensibilidade orgânica, às sensações; sentido relacionado às emoções e aos sentimentos; sentido relacionado à direção e orientação das ações: sentido relacionado à razão, à significação. É na tessitura dessas dimensões que signos se produzem, sempre em "relação $a$ " outros ou algo. Os sentidos emergem como resultantes dessas relações. (Smolka, 2006b, p. 108)

Nessa perspectiva, a compreensão e a complexidade do processo de produção de sentidos, que envolve e condensa múltiplas dimensões em tensão dialética, é completamente diferente da proposta de González Rey ${ }^{2}$ de sentido pessoal como uma dimensão subjetiva, assim como são muito diversas as leituras e interpretações de Vygotsky e de Bakhtin.

As contribuições profícuas e promissoras de Vygotsky e de Bakhtin na compreensão da significação argumentam que a linguagem, como produto da atividade, como produção humana, produz o sujeito na relação com o outro. A palavra, como signo produzido e resultante das relações dos sujeitos, opera transformações nas atividades e nos sujeitos, afetando-os nas práticas sociais. Concebe-se que a significação emerge nas relações, como atividade humana. Vygotsky (1996, p. 117) salienta que os

2 González Rey (1999) faz severas críticas a Bakhtin pelo fato de ter assumido a ideologia como uma mera expressão semiótica e o sujeito concreto como apenas um eco de forças objetivas que o determinam. Assim, no seu entendimento, Bakhtin manifesta um total desconhecimento do lugar da subjetividade nos processos psicológicos, e a semiótica é por ele compreendida como expressão objetiva dos fenômenos sociais e econômicos, e não como um nível constitutivo da subjetividade humana. 
conteúdos dos signos "são extraídos pelo homem da ideologia do meio que o rodeia".

Bakhtin (ou Volochinov 1992a, p. 95) afirma que a palavra é um signo ideológico, "a palavra está sempre carregada de um conteúdo ou de um sentido ideológico ou vivencial". Assim, os processos de significação, a enunciação ou um enunciado estão vinculados à interação de vozes e/ou perspectivas ideológicas e/ou posições sociais e/ou à arena de disputa/luta na estrutura desigual e contraditória da sociedade, e "psiquismo e ideologia impregnam-se mutuamente no processo único e objetivo das relações sociais" (Bakhtin, 1992a, p. 66).

A subjetividade, por sua vez, é permanentemente constituinte e constituída. Está na interface do psicológico e das relações sociais. Bakhtin (1992a), para se referir a esta interface - que ele apresenta como o limite do organismo e do mundo exterior - emprega a noção de uma fronteira na qual o psiquismo subjetivo se localiza. A fronteira é entendida por Bakhtin como a região limítrofe de duas esferas da realidade que se encontram no signo: o organismo e o mundo.

A subjetividade permeia os processos psicológicos e extrapola os limites da individuação de um sujeito. Ela se realiza no processo de conversão das relações interpsicológicas em relações intrapsicológicas pela mediação semiótica.

Para Bakhtin (1993, p. 58), "cada um ocupa um único e irrepetível lugar, cada ser é único". Refere-se à unicidade e singularidade. Na obra Para uma filosofia do ato (1993, p. 58), Bakhtina ao discutir o não-álibi no ser, afirma que não existe álibi para a existência; porém o fato do não-álibi no ser - de que cada ser é único, de que cada um ocupa um único e irrepetível lugar, como argumenta Amorim (2009) está longe de qualquer empreendimento solipsista ou introspectivo na busca de sentido, mas já aparece como um eixo da obra bakhtiniana a questão da alteridade.

Para Vygotsky, o outro é também a referência do sujeito. Esse outro apresenta e representa muitos e diversos "outros": o Outro presente, o ausente, o simbólico, o consciente, o inconsciente, o afetivo, o semiótico, o corpóreo, o outro eu.

Está posta a questão da alteridade para os dois autores, assim como a do processo de constituição do sujeito que se dá nas e pelas relações sociais pelas mediações na linguagem no campo das relações intersubjetivas.

Nessa trama das relações sociais são instituídos os significados e forjados os sentidos das palavras, no movimento de objetivar e subjetivar dos sujeitos, de acordo com sua compreensão de mundo, do outro e de si próprios nos (des)encontros da vida.

Bakhtin aprofunda a noção de alteridade e o princípio da dialogia, que implica o encontro (natureza social) e as vozes em um espaço e um tempo social e histórico. Para Bakhtin, é o sujeito situado, tendo sempre presente sua situação social e histórica concreta (Sobral, 2008). Vygotsky e Bakhtin potencializam a construção negociada, mediada dos sentidos.

A estruturação da consciência é histórica e semiótica e a constituição do sujeito se dá na forma de drama, pois a vida é dramática e tem inúmeras conexões e interconexões permanentes - com saltos e rupturas, quedas e suturas em uma engrenagem potente e pulsante, atravessada pelos processos de significação. Como dar conta dessa complexidade e totalidade que a vida vivida por cada um e ao mesmo tempo por todos - sem parar, sem pausa, sem retroceder - em um movimento dialético que permite viver e ver o vivido, apostar no devir e ver pelo retrovisor aquilo que não pode voltar atrás, porque já foi, já aconteceu, embora possa ser (re)inventado, recordado e (re)construído?

Para o sujeito não existe o sem sentido, o vazio, mas a negatividade e a ausência de sentido, o que já foi, o que é e o devir com seus múltiplos sentidos e significados. Pode-se negar, ocultar, ignorar, esquecer, mascarar, mas as impressões, as marcas, os vestígios, as pistas, os rastros já ficaram inscritos nos corpos, nos signos, nas pegadas e na imaginação do passado, seja este recente ou remoto, no presente, na memória do futuro (Bakhtin, 1992b).

Todo esse processo de consciência de outrem e autoconsciência e de memória (coletiva, dialógica, discursiva, polissêmica, polifônica, etc., sempre mediadas) é potencializado pelas experiências (histórica, social, duplicada, alheia, própria...) que ativam lembranças e sonhos, imaginação e invenção, que são potencializados pelas múltiplas dimensões dos sentidos nas relações intersubjetivas.

Experiências, como potentes vivências, (re)constroem memórias (futuro, presente e passado) e modos de conviver com o inusitado, de reinventar paisagens e sonhos, de definir atos responsáveis que orientam processos de constituição da subjetividade. $\mathrm{O}$ sujeito pode ver-se a si mesmo e ver o outro e a situação em que ambos vivem - sempre em acabamentos provisórios, a partir dos quais vão se constituindo na sua incompletude. As experiências vividas são momentos constituintes da vida do sujeito - que é vivida dramaticamente - e compõem o drama que o constitui. 
O eu sempre será visto pelo outro desde um lugar que não o do próprio eu; nisso, o eu vai se constituindo diferente de si mesmo, sendo um outro para o outro e para si mesmo. Assim, o outro tem, relativamente ao eu, um excedente de visão (Geraldi, 2003, pp. 43-44), isto é, uma experiência de si que o próprio eu não tem, mas que pode ter a respeito dele. O outro é condição necessária - mas não suficiente - à existência e à incompletude do eu, pois é necessário o olhar do outro; mas o eu regressa a si mesmo e à sua incompletude, não vendo o que o outro viu, mas o que foi possível para o eu. Desse modo, está posta a impossibilidade de acabamento e de completude do eu e do outro. Além disso, a experiência do outro, mesmo sendo do "eu", é inacessível.

Pensar a constituição do sujeito e da subjetividade na abordagem sócio-histórica e na perspectiva histórico-cultural agregando alguns conceitos de Bakhtin torna mais complexa a concepção de Vygotsky, o qual diz que as relações sociais são fundantes dos sujeitos. Para ambos, a relação EuOutro é o princípio constitutivo do sujeito. A alteridade e a dialogia são os pilares do pensamento bakhtiniano.

Bakhtin salienta a diferença de lugares, de posições e de valores de cada sujeito. Desse modo, Amorim (2003, p. 14), enfatizando o pensamento bakhtiniano, afirma: "Meu olhar sobre o outro não coincide nunca com o olhar que ele tem de si mesmo". Bakhtin (1992b) fala da não coincidência com o outro e da não coincidência consigo próprio. Pressupõe o "Outro como existente, ser expressivo e falante" que "nunca coincide consigo mesmo e por isso é inesgotável em seu sentido e significado" (Smolka, 2006c, p. 17), pressupondo o outro como existente e reconhecido pelo "eu" como Outro que não eu. É a relação dialógica que possibilita a relação entre o Eu e o Outro.

Essa (não)coincidência do sujeito consigo mesmo nos mostra como a dinâmica da personalidade é drama; como o drama vivido e experimentado pelo sujeito se entretece e se constitui na trama das relações e das experiências histórica e culturalmente partilhadas. (Smolka, 2006c, p. 17)

A constituição do sujeito vivida como drama potencializa a capacidade de criar e abrir-se para o inusitado, para o não coincidente, para o inesperado, não se esquecendo de lutar contra as desigualdades sociais e de não assumir uma posição de indiferença em relação ao outro. Nesse momento, abra-se ao outro na incompletude e no inacabamento deste texto.

\section{REFERÊNCIAS}

Amorin, M. (2003). A contribuição de Mikhail Bakhkin: a tripla articulação ética, estética e epistemológica. Em M. T. Freitas, S. Jobim e Souza \& S. Kramer (orgs.), Ciências Humanas e pesquisa: Leituras de Mikhail Bakhtin (pp. 11-25). São Paulo: Cortez.

Amorin, M. (2009). Para uma filosofia do ato: 'válido e inserido no contexto'. Em B. Brait (org.), Bakhtin, dialogismo e polifonia (pp. 17- 43). São Paulo: Contexto.

Bakhtin, M. (1992b). Estética da criação verbal. São Paulo: Martins Fontes.

Bakhtin, M. (1993). Para uma filosofia do ato. (Carlos A. Faraco e Cristovão Tezza, trad.), Edição Americana Toward a Philosophy of the act. Austin: University of Texas Press.

Bakhtin, M. (Volochinov, V. N.) (1992a). Marxismo e filosofia da linguagem. São Paulo: Hucitec.

Figueiredo, L. C. M. (1991). Matrizes do pensamento psicológico. Petrópolis, RJ: Vozes.

Geraldi, J. W. (2003). A diferença identifica. A desigualdade deforma. Percursos bakhtinianos de construção ética e estética. Em M. T. Freitas, Jobim e S. Souza \& S. Kramer (orgs.), Ciências Humanas e pesquisa: Leituras de Mikhail Bakhtin (pp. 39-56). São Paulo: Cortez.

Góes, M. C. R. (1993). Os modos de participação do outro nos processos de significação do sujeito. Temas em Psicologia, 1(1), 1-5.

González Rey, F. (1997). Epistemología cualitativa y subjetividad. São Paulo: Educ.

González Rey, F. (1999). La investigación cualitativa en psicología: rumbos y desafios. São Paulo: Educ.

González Rey, F. (2001a). O enfoque histórico-cultural e seu sentido para a psicologia clínica: uma reflexão. Em A. M. B. Bock, M. G. M. Gonçalves \& O. Furtado (orgs.), Psicologia sócio-histórica: uma perspectiva crítica em psicologia (pp. 193-214). São Paulo: Cortez.

González Rey, F. (2001b). La categoria de sentido subjetivo y su significacion en la construcción del pensamiento psicológico. Contrapontos, 1(2), 13-28.

González Rey, F. (2005). O valor heurístico da subjetividade na investigação psicológica. Em F. González Rey (org.), Subjetividade, complexidade e pesquisa em psicologia (pp. 2751). São Paulo: Pioneira Thomson Learning.

Molon, S. I. (2003). Subjetividade e constituição do sujeito em Vygotsky. Petrópolis, RJ: Vozes.

Molon, S. I. (2009). As contribuições de Vygotsky na formação de educadores ambientais. Em C. F. B. Loureiro, P. P. Layrargues \& R. S. Castro (orgs.), Repensar a educação ambiental: um olhar crítico (pp. 141-172). São Paulo: Cortez.

Pino, A. (1992). As categorias de público e privado na análise do processo de internalização. Educação e Sociedade, 42 (2), 315327.

Pino, A. (2005). As marcas do humano: às origens da constituição cultural da criança na perspectiva de Lev S. Vigotski. São Paulo: Cortez.

Smolka, A. L. B. (2000). O (im)próprio e o (im)pertinente na apropriação das práticas sociais. Cadernos Cedes, 50 (1), $26-40$. 
Smolka, A. L. B. (2004). Sentido e significação. Parte A - Sobre significação e sentido: uma contribuição à proposta de rede de significações. Em M. C. Rossetti-Ferreira, K. S. Amorim, A. P. S. Silva \& A. M. A. Carvalho (orgs.) Rede de significações e o estudo do desenvolvimento humano (pp. 35-49). Porto Alegre: Artmed.

Smolka, A. L. B. (2006a). Enseñar y significar: las relaciones de la enseñanza en cuestión. $\mathrm{O}$ de las (no) coincidencias en las relaciones de enseñanza. Cultura y Educación. 1 (18), 3-14.

Smolka, A. L. B. (2006b). Experiência e discurso como lugares de memória: a escola e a produção de lugares comuns. Proposições, 2 (17), 99-118.

Smolka, A. L. B. (2006c). Ensinar e significar: as relações de ensino em questão: ou das (não)coincidências nas relações de ensino. (mimeografado).

Smolka, A. L. B., Góes, M. C. R. \& Pino, A. (1998). A constituição do sujeito: uma questão recorrente?. Em J. Wertsch,, P. Del Rio \& A. Alvarez (orgs), Estudos socioculturais da mente (pp. 143-158). Porto Alegre: ArtMed.

Sobral, A. (2008). Ato/atividade e evento. Em B. Brait (org.), Bakhtin: Conceitos-chave (pp. 11-36). São Paulo: Contexto.

Thompson, E. P. (1981). A miséria da teoria ou um planetário de erros. Uma crítica ao pensamento de Althusser. Rio de Janeiro: Zahar.
Vigotski, L. S. (1996). Teoria e método em psicologia. São Paulo: Martins Fontes.

Vigotski, L. S. (2000). Manuscrito de 1929. Educação \& Sociedade, 71, 45-78.

Vigotski, L. S. (2001). A construção do pensamento e da linguagem. São Paulo: Martins Fontes.

Vygotski, L. S. (1995). Obras Escogidas III. Problemas del desarrollo de la psique. Historia del desarrollo de las funciones psíquicas superiores. Madrid: Visor.

Vygotsky, L. S. (1993). Pensamento e linguagem. São Paulo: Martins Fontes.

Recebido em 22/06/2011

Aceito em 22/11/2011
Endereço para correspondência:

Susana Inês Molon. Rua São Leopoldo, 302, Bairro Cassino, CEP 96205-180, Rio Grande-RS. E-mail: susana.molon@furg.br. 